Check for updates

Cite this: RSC Adv., 2017, 7, 34473

\title{
Protective effect and mechanistic evaluation of linalool against acute myocardial ischemia and reperfusion injury in rats
}

\author{
Xiao-Hui Zheng, (ID *ab Chun-Ping Liu, ${ }^{\mathrm{b}}$ Zeng-Guang Hao, ${ }^{\mathrm{b}}$ Yan-Fang Wang ${ }^{\mathrm{b}}$ \\ and Xian-Li Lib
}

The present study describes the protective effect of linalool against the isoproterenol (ISO)-induced myocardial infarction in adult male Sprague Dawley rats. The results of the study showed that linalool causes considerable improvement of the ischemic heart via number of mechanisms. It has been found that it causes significant reduction in the level of serum LDH and CK-MB levels together with improvement in LVSP, $+\mathrm{d} p / \mathrm{d} t_{\max }$ and $-\mathrm{d} p / \mathrm{d} t_{\max } 24 \mathrm{~h}$ after ischemia/reperfusion (I/R). Use of linalool also showed reduction in the levels of Tn-T (cardiac biomarker) and cytokines, such as TNF- $\alpha$ and IL- 6 . Furthermore, significant inhibition of MDA and MPO activities was also reported in the linalool receiving group together with restoration of the decreased SOD and GPx activities. The western blot analysis of linalool was also carried out to determine its effect on the expression of NF- $\kappa \mathrm{B}$. The effect of linalool was found in the results of the histopathology analysis, which confirmed that the linalool treated group showed restoration of microstructural changes in cardiac tissues as compared to the control. Linalool showed significant cell death and apoptosis of $\mathrm{H} 9 \mathrm{c} 2$ cells during I/R. It has been found that linalool showed up-regulation of VEGF-B mRNA and protein levels, which promoted the activation of Akt and the inhibition of GSK3 $\beta$ as a possible additional mechanism to exert a cardioprotective effect.

Received 17th January 2017

Accepted 13th June 2017

DOI: $10.1039 / c 7 r a 00743 d$

rsc.li/rsc-advances
In this regard, natural products, because of their very high antioxidant capacity, have been found to be very useful in treating reperfusion injury and to give symptomatic relief by inhibition of the reactive mediators. ${ }^{10-12}$ They are also able to block the apoptotic process and this causes reduction in cardiac injury induced by ischemic/reperfusion ( $\mathrm{I} / \mathrm{R}$ ) injury. Among the diverse array of the natural compounds, linalool, a major component of the essential oil identified as a volatile component from many aromatic plant species, has been reported to exhibit numerous pharmacological activities, such as antioxidant, ${ }^{13}$ anti-inflammatory, ${ }^{14,15}$ hepatoprotective and lipopolysaccharide (LPS) induced acute lung injury in mice. ${ }^{16}$ Concerning its tremendous antioxidant potential, no exhaustive report has discussed its effect against the I/R injury. Thus in the present study, it was intended that the protective effect of linalool against the $\mathrm{I} / \mathrm{R}$ injury in rats together with the probable mechanism of action would be elucidated.

\section{Result}

\section{Effect of linalool on the ISO-induced myocardial necrosis in rats}

As shown in Fig. 1, the outcome of linalool on the serum level of the lactate dehydrogenase (LDH) and creatine kinase-MB (CK-MB) in the myocardial injury induced by isoproterenol (ISO) was determined. The study showed that the serum levels of both CK-
${ }^{a}$ Department of Cardiology, Henan Provincial Peoples Hospital, Zhengzhou, 450000, Henan, China. E-mail: ayzxhhxz@hotmail.com; Fax: +86-372-5108915; Tel: +86372-5108915

${ }^{b}$ Second Department of Internal Medicine, Anyang District Hospital Henan Province, Anyang, 455000, Henan, China 
A

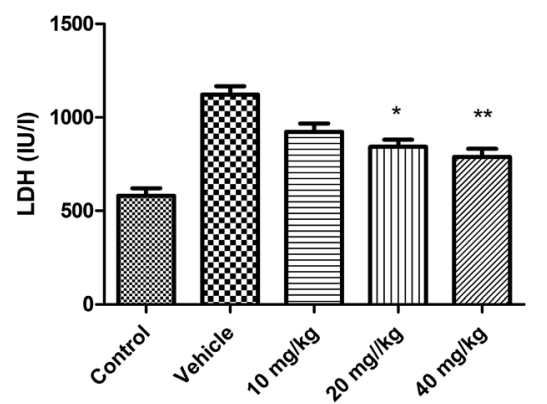

B

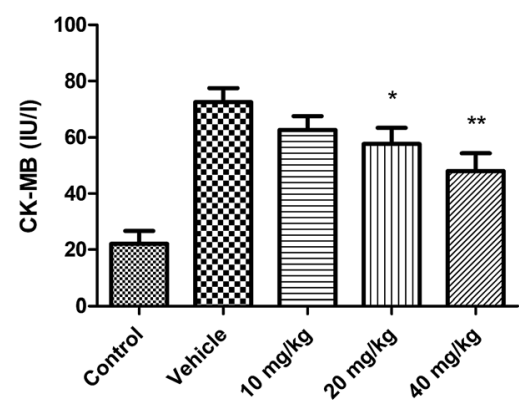

Fig. 1 Effect of linalool on the serum (A) LDH and (B) CK-MB levels in ISO-induced cardiac injury. $* P<0.05$ and $* * P<0.01$ versus the vehicle treated group.

$\mathrm{MB}$ and $\mathrm{LDH}$ were found to be significantly elevated in the ISOtreated rats, whereas in the group treated with linalool there was a noteworthy decline in serum LDH and CK-MB levels as compared with the results for the ISO treated group.

\section{Effect of linalool on myocardial ability}

In this study, the effect of linalool on left ventricular systolic pressure (LVSP) and $\pm \mathrm{d} p / \mathrm{d} t_{\max }$ of the left ventricle (LV) during myocardial I/R were determined. As shown in Fig. $2 \mathrm{~A}-\mathrm{C}$, in comparison with the ISO treated animals, the linalool treated animals showed considerable improvement in LVSP, $+\mathrm{d} p / \mathrm{d} t_{\max }$ and $-\mathrm{d} p / \mathrm{d} t_{\max } 24 \mathrm{~h}$ after $\mathrm{I} / \mathrm{R}$.

\section{Effect of linalool on myocardial infarct volume}

As shown in Fig. 2D, it has been found that in linalool treated animals, the infarct size has been significantly reduced when compared with the ISO treated group. Thus, it has been shown that linalool is effective in modulating the myocardial $I / R$ injury.

\section{Effect of linalool on serum levels of Tn-T, TNF- $\alpha$ and IL-6}

As shown in Fig. 3, it was found that the levels of cardiac specific troponin (Tn-T), tumour necrosis factor- $\alpha$ (TNF- $\alpha$ ) and interleukin-6 (IL-6) were found to be considerably enhanced in rats treated with ISO. Whereas, in linalool treated rats, the levels of these markers were found to be considerably decreased.

\section{Effect of linalool on production of MDA and on MPO, SOD and GPx levels}

As shown in Fig. 4, the generation of malondialdehyde (MDA) and myeloperoxidase (MPO) were significantly elevated. The activities
A

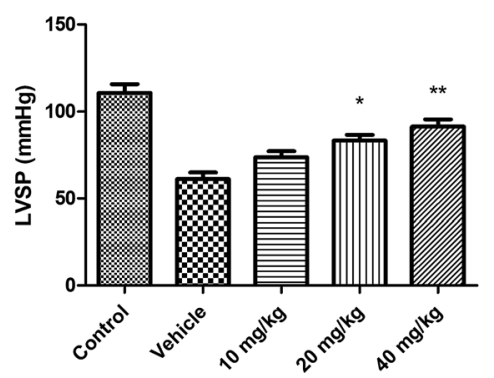

C

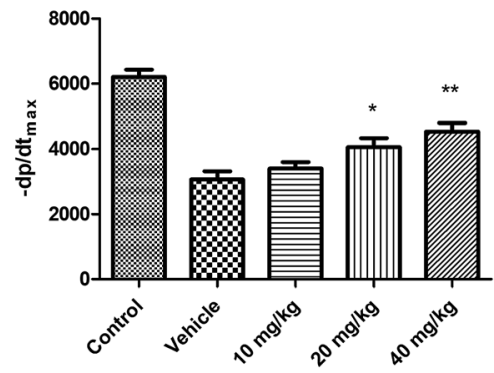

B

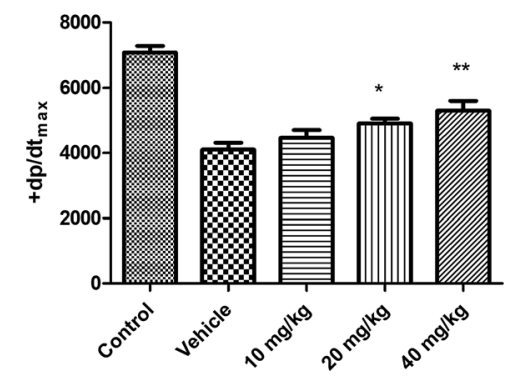

D

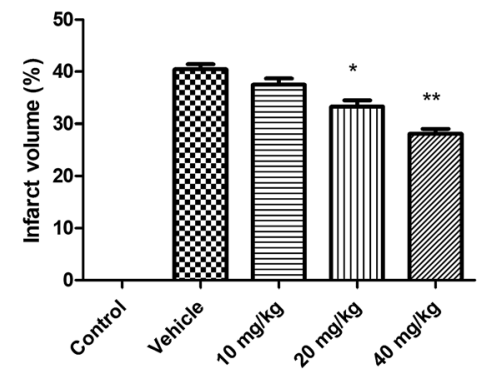

Fig. 2 Effect of linalool on the (A) LVSP, (B) $\pm d p / d t_{\max }(C)-d p / d t_{\max }$ and (D) infarct volume after I/R in experimental animals. *P< 0.05 and $* * P<$ 0.01 versus vehicle treated group. 
A

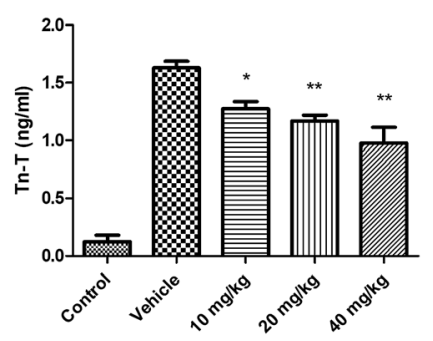

B

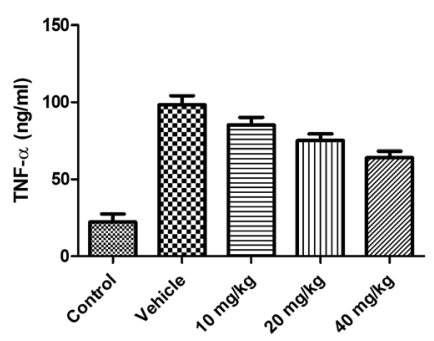

C

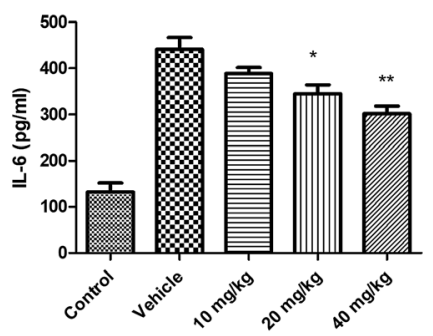

Fig. 3 Effect of linalool on the myocardial function and infarct volume. Where, (A) Tn-T, (B) TNF- $\alpha$ and (C) IL- 6 levels. *P<0.05 versus vehicletreated group. $* * P<0.01$ versus vehicle-treated group.

A

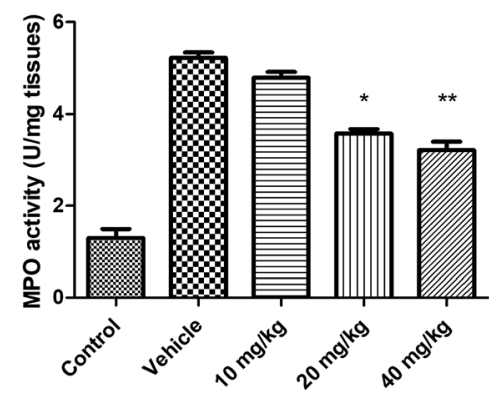

C

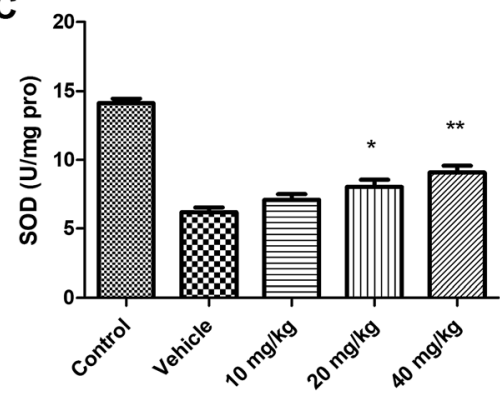

B

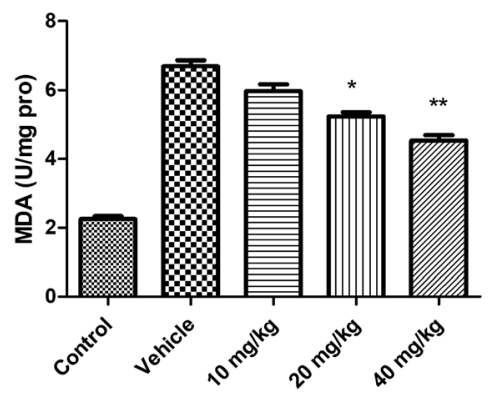

D

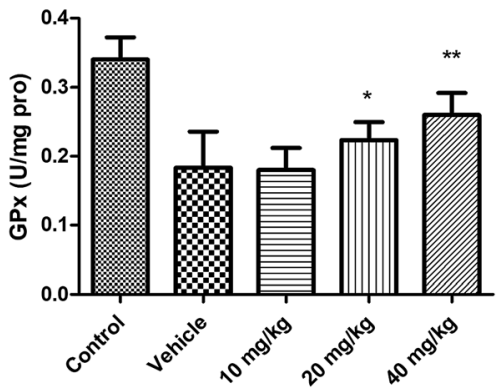

Fig. 4 Effect of linalool on production of (A) MDA and on (B) MPO, (C) SOD and (D) GPx levels. ${ }^{*} P<0.05$ versus vehicle treated group; $* * P<0.01$ versus vehicle treated group.

of glutathione peroxidase-1 (GPx) and superoxide dismutase (SOD) were found to be considerably decreased in the ISO treated animals. Furthermore, as the treatment with linalool started, it significantly inhibited the MDA and MPO activities as well as restoring the decreased SOD and GPx activities.

\section{Effect of linalool on pathological changes}

As shown in Fig. 5, after the first $24 \mathrm{~h}$, the infarct area was prominent with widespread tissue necrosis, together with an increase in infiltration, and signs of haemorrhage. Whereas, in rats treated with linalool, there were signs of significant
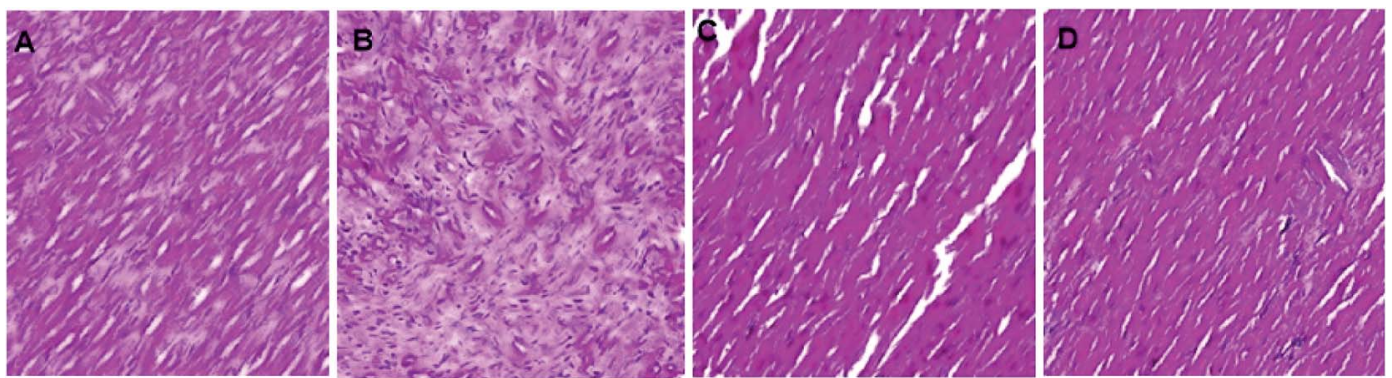

Fig. 5 Effect of linalool on the histopathology of cardiac tissues, where, (A): vehicle, (B): linalool (10 mg kg $\left.{ }^{-1}\right)$, (C): linalool (20 mg kg $\left.{ }^{-1}\right)$, (D): linalool (40 $\mathrm{mg} \mathrm{kg}^{-1}$ ). (Magnification: 100×). 


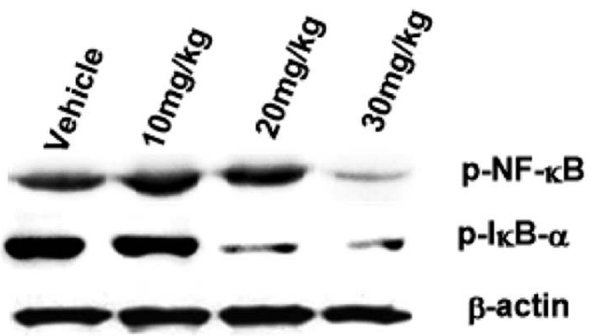

Fig. 6 Effect of linalool on $\mid \kappa B-\alpha$ and NF- $\kappa$ B phosphorylation. restoration of the normal microstructural changes in a dosedependent manner.

Western blotting analysis of the effect of linalool on IкB- $\alpha$ and NF- $\kappa$ B phosphorylation

As shown in Fig. 6, it was found that linalool causes significant inhibition of phosphorylated I $\kappa \mathrm{B}-\alpha$ and NF- $\kappa \mathrm{B}$ expression when compared to the myocardial tissues after I/R.
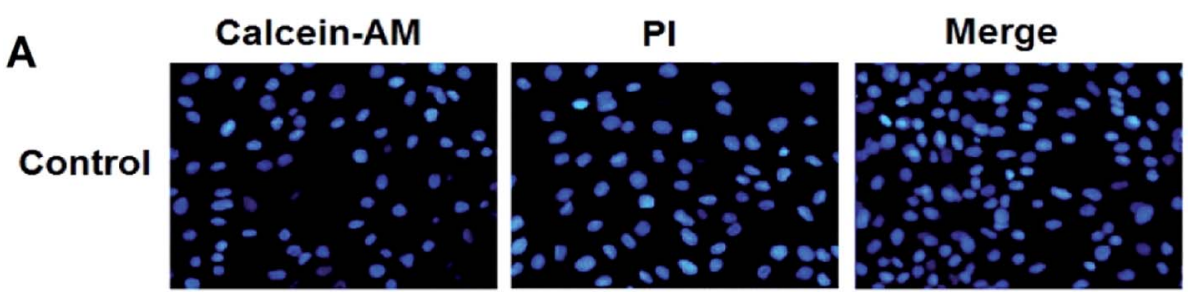

IR
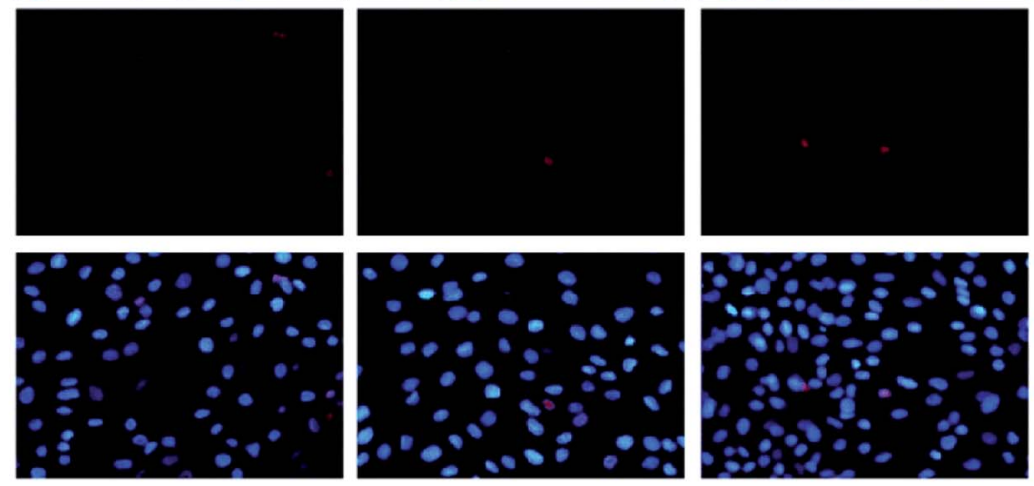

B
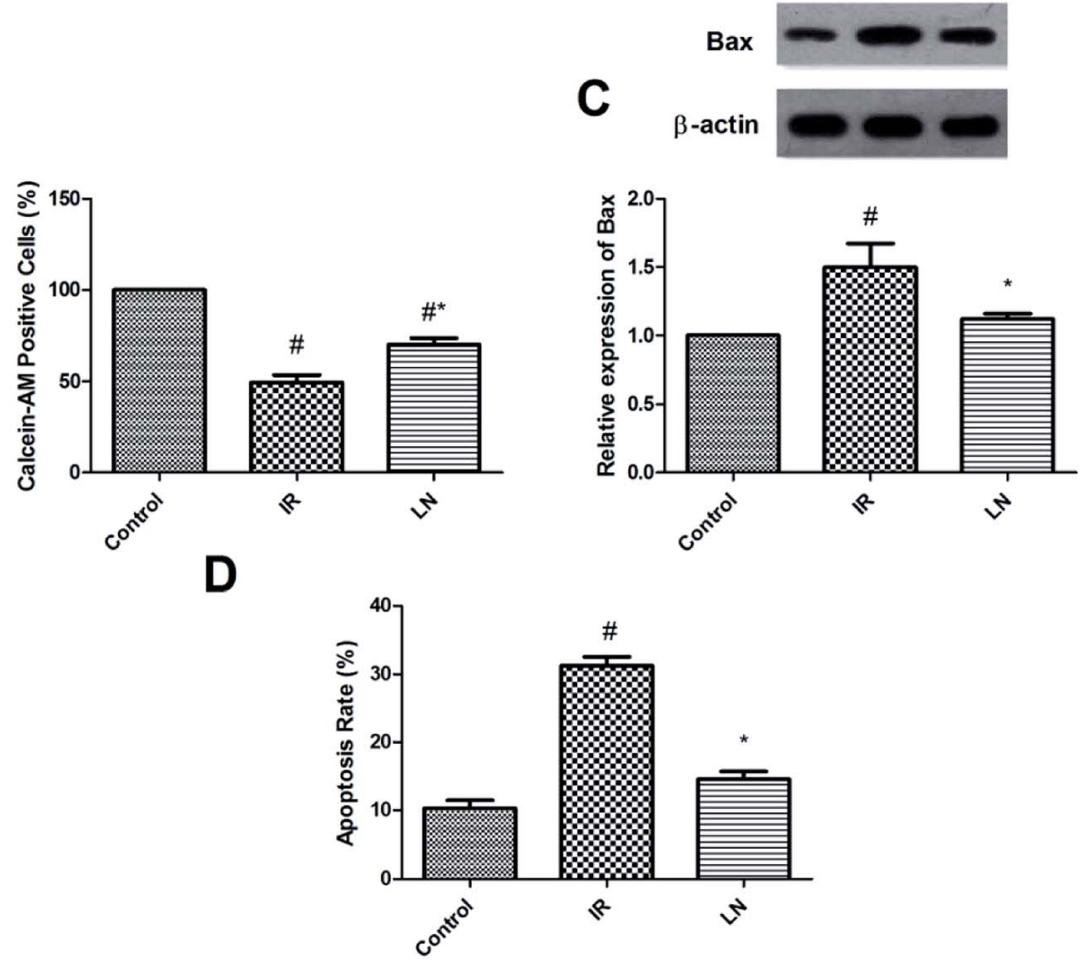

Fig. 7 Linalool (LN) causes attenuation of I/R induced cell death and apoptosis either in vitro or in vivo. (A) Evaluation of cell death in H9c2 cells using calcein-AM/PI double staining; (B) the cells survival rate; (C) the protein level of Bax in heart tissues was determined using a western blot technique; (D) apoptotic cells were detected using flow cytometry. $\# P<0.05$ versus control group, $* P<0.05$ versus I/R group. 
Effect of linalool on the $\mathbf{I} / \mathrm{R}$ induced cell death and apoptosis of cardiomyocytes

The next part of study was aimed at elucidating the effect of linalool on the cell death occurring during the I/R. For this experiment, calcein-AM/propidium iodide (PI) double staining was carried out. It has been found that a large quantity of $\mathrm{H} 9 \mathrm{c} 2$ cells (fetal rat cardiomyocyte derived cell line) were reported to be dead after the I/R, whereas the use of linalool inhibited the cell death when compared to the results obtained with the I/R group as shown in Fig. 7A and B. The effect of linalool on the apoptosis was also quantified with using western blot analysis and quantification of the expression of BCL2-associated X protein (Bax), an apoptotic protein in heart tissue. Results showed that the level of Bax was found to be elevated more in the $\mathrm{I} / \mathrm{R}$ group than in the control group. However, the group receiving linalool showed significant down-regulation of the expression of the Bax protein level (Fig. 7C). As shown in Fig. 7D, it has been found that the rate

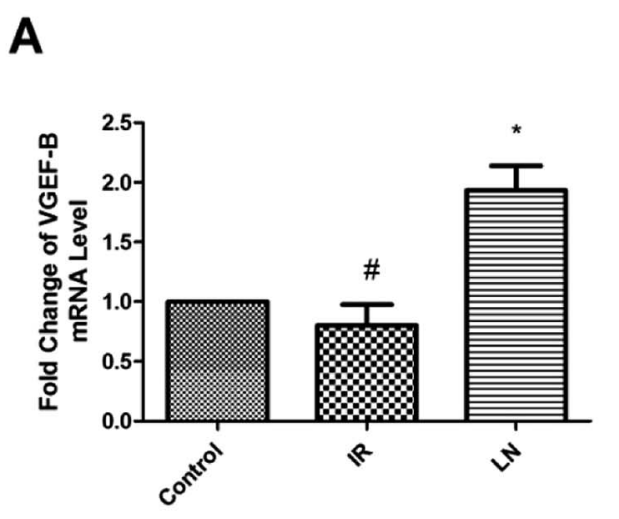

B

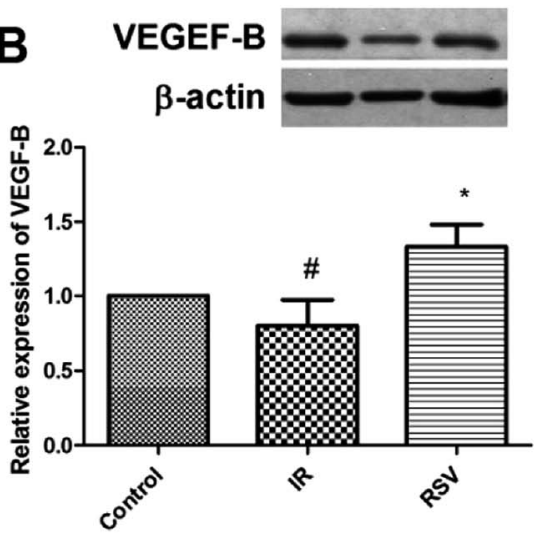

D

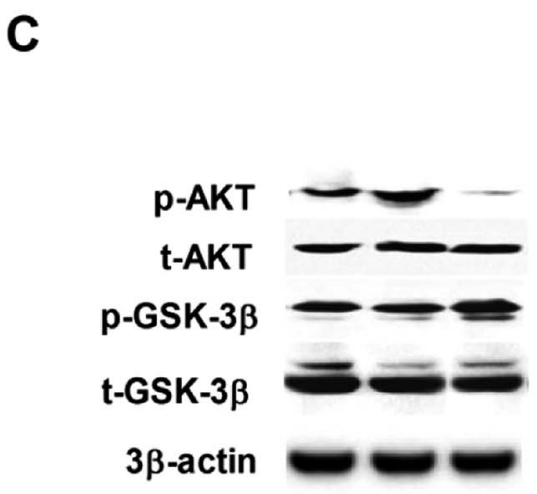

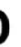

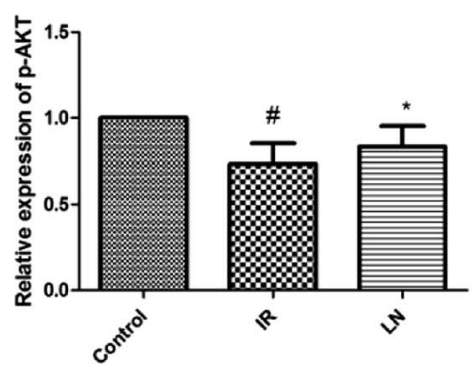

of apoptosis was significantly attenuated under influence of linalool.

Effect of linalool on the expression of VEGF-B and regulated Akt/GSK3 $\beta$ signaling pathway

As shown in Fig. 8A and B, the administration of linalool (LN receiving group) causes significant up-regulation of messenger ribonucleic acid (mRNA) and protein levels of vascular endothelial growth factor B (VEGF-B) when compared with the results for the I/R group. Furthermore, the level of phosphorylated protein kinase $\mathrm{B}$ (Akt) (Ser473) and glycogen synthase kinase 3 beta (GSK3 $\beta$ ) (Ser 9) were also found to be up-regulated in the linalool treated group (Fig. 8C and D).

Effect of linalool on the echocardiographic indicators of cardiac morphometry and function

The results of results of echocardiographic analysis are shown Table 1. It has been found that linalool treatment produced

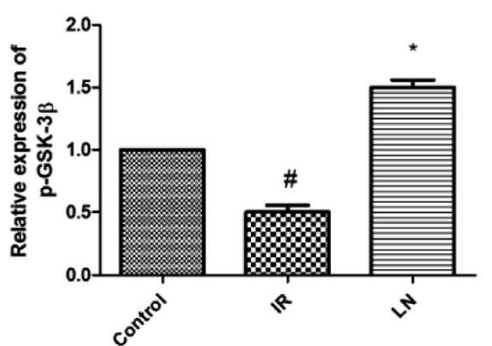

Fig. 8 Linalool regulated the VEGF-B and Akt/GSK3 $\beta$ signaling pathways. (A) The linalool up-regulated the mRNA level of VEGF-B in heart tissues; (B) linalool up-regulated the protein level of VEGF-B in heart tissues; (C) linalool up-regulated phosphorylated Akt(Ser473) and GSK3 $\beta$ (Ser9) protein level in heart tissues; (D) quantification of phosphorylated Akt and GSK3 $\beta$ in heart tissues. $\# P<0.05$ versus control group, * $P$ $<0.05$ versus I/R group. 
Table 1 The effect of linalool on cardiac function in rats (echo readings) ${ }^{a}$

\begin{tabular}{lcc}
\hline Parameters & Pre & Post \\
\hline PWT $(\mathrm{mm})$ & $1.40 \pm 0.02$ & $1.53 \pm 0.05^{*}$ \\
LVM $(\mathrm{g})$ & $1.12 \pm 0.02$ & $1.31 \pm 0.03$ \\
AD $(\mathrm{mm})$ & $3.25 \pm 0.22$ & $3.58 \pm 0.31$ \\
ESV $(\mu \mathrm{l})$ & $145 \pm 9$ & $198 \pm 11^{* *}$ \\
EDV $(\mu \mathrm{l})$ & $323 \pm 14$ & $378 \pm 18^{* *}$ \\
EF $(\%)$ & $55.1 \pm 2.4$ & $47.6 \pm 2.6^{* *}$ \\
CI $\left(\mu \mathrm{l}[\mathrm{min} \mathrm{g}]^{-1}\right)$ & $185 \pm 5$ & $167 \pm 8^{* *}$
\end{tabular}

${ }^{a}$ The values are mean \pm SEM. AD: aortic diameter, CI: cardiac index, EDV: end-diastolic volume of the LV, EF: ejection fraction of the LV, ESV: end-systolic volume, LVM: left ventricular mass, PWT: left ventricular posterior wall thickness ${ }^{*} P<0.05$ and ${ }^{*} P<0.01$ versus vehicle treated group.

considerable improvement in the heart function as shown by the improvement in the posterior wall thickness of the LV together with an increase in the mass of the LV. The end-systolic volume (ESV) was also found to be increased in rats treated with linalool. A significant reduction was observed in the ejection fraction with reduction in the clearance suggesting the protective role of linalool in myocardial $\mathrm{I} / \mathrm{R}$ injury.

\section{Discussion}

In the present investigation, it has been observed that the myocardial ability of the rats receiving the linalool showed significant improvement when compared to the I/R groups in the I/R challenge study. This was further supported by the reduction in the infarct size, which was subsequently found to agree with the results of the histopathological analysis. The linalool would be able to modulate the cardiac function and it was suggested that it would be able to inhibit the necrosis of the cardiac tissues.

As shown in recent studies, the Tn-T is well established as a significant marker of cardiac damage. ${ }^{17,18}$ Thus, in the present study, it was shown that linalool caused significant reduction in the serum level of Tn-T together with prominent protective action against myocardial degradation. It has also been well established that the generation of free radicals following myocardial injury plays a significant role in the progression of the damage. These radicals are believed to cause destruction of proteins, DNA, and lipids, together with severe membrane damage which ultimately induces the death of the tissue. ${ }^{19-21}$ In the present study, it was found that linalool causes a reduction in MDA production and restored the level of SOD and GPx in affected cardiac tissue to a major extent. This suggests that linalool could exert its action to protect the myocardial damage by possibly limiting the generation of free radicals which can prevent the necrosis of the tissue, and thus, tissue activity will be restored.

The myocardial damage may be the result of the infiltration of polymorphonuclear leukocytes (PMNs), and can cause damage of the cardiomyocytes via the generation of inflammatory mediators. ${ }^{22-25}$ Thus, limiting its infiltration may have some protective effect against the myocardial damage in an I/R injury. It mediates its action via generation of the ROS, and other hydrolytic enzymes which might lead to the progression of micro-structural injury. It has been found that, after the I/R insult, the activity of MPO was significantly elevated together with an increased leukocyte accumulation. Thus, it has been found that linalool reduces the membrane permeability towards the PMN and MPO activity in the ischemic myocardial tissues. Earlier studies have stated that the role of the activation

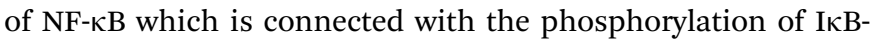
$\alpha$ and transport of p65 from the nucleus. ${ }^{26,27}$ In the present study, it was found that linalool was able to inhibit the phosphorylation of $\mathrm{I} \kappa \mathrm{B}-\alpha$ together with reduction of $\mathrm{NF}-\kappa \mathrm{B}$ in myocardial tissues. Thus, it has been suggested that the protective effects of linalool could be attributed to the attenuation effect which might be because of the signals of the inflammation via inhibition of the NF- $\kappa \mathrm{B}$ activation.

The role of VEGF-B in the cardiovascular system is still a matter of debate. ${ }^{28}$ Therefore, not much is known about the involvement of VEGF-B in the progression or generation of MI. Thus, in the present study, the role of VEGF-B in the cardioprotective effect of linalool as suggested by previous experiments was investigated. The results of the study showed that linalool causes significant up-regulation of VEGF-B expression in the Langendorff perfusion assay. In an extension of this study, an in vitro study was carried out to look at the role of VEGF-B in H9c2 cells because of its excellent function in the I/R injury model. ${ }^{29,30}$ As suggested previously, the ROS is the important predictor for the progression of an MI, thus to replicate this behaviour in an in vitro system, rotenone was used. The rotenone was believed to be the inhibitor of mitochondrial electron transport chain complex I, and promotes the production of ROS in numerous cells. Previous studies suggested that rotenone causes the induction of ROS-promoted cellular death in $\mathrm{H} 9 \mathrm{c} 2$ cells and generates ischemia in renal cells. ${ }^{31,32}$ Thus, in accordance with the earlier experiments, the results showed that rotenone treatment can mimic $\mathrm{I} / \mathrm{R}$ in rat cardiomyocytes (Fig. 7A and B). In the flow cytometric cell apoptosis assay, it was found that linalool causes significant inhibition of $\mathrm{I} / \mathrm{R}$ induced apoptosis (Fig. 7D) together with modulation of the Bax protein expression (Fig. 7C) which might be suggested as a possible mechanism for the cardioprotective action of linalool. Recent studies concluded that activated Akt mediated inhibition of GSK3 $\beta$ could provide protection to the heart from myocardial I/R injury, suggesting the negative role of GSK3 $\beta$ in myocardial I/R. ${ }^{33,34}$ The cross-talk between Akt and GSK3 $\beta$ was also showed that Akt is upstream of GSK3 $\beta$. Thus, in the present study, the effect of linalool on this complex was evaluated. As shown in Fig. 8, it has been found that linalool causes activation of Akt and inhibition of GSK3 $\beta$ after administration of linalool treatment (phosphorylation in Ser9 of GSK3 $\beta$ means its activity is inhibited).

The electrocardiogram (ECG) is an important tool for assessing the protective effect against the myocardial damage induced by ischemia. A study by Preda and Burlacu describes excellently the use of ECG in validating the myocardial I/R procedures in mice. ${ }^{35}$ Thus, in the present study, we 
investigated the protective effect of linalool in myocardial $\mathrm{I} / \mathrm{R}$ injury via ECG. It has been found that linalool causes growth related increase in posterior ventricular wall thickness, end systolic and diastolic volumes, and reduces the ejection fraction.

\section{Experimental}

\section{Chemicals}

Linalool and the other chemicals used in the present study were obtained from Sigma-Aldrich (USA).

\begin{abstract}
Animals
For the study, adult male Sprague Dawley (240-270 g) rats were obtained from the institutional animal house and were caged individually in polypropylene cages under controlled temperature and humidity with alternate, dark and light cycle and food and water ad libitum. The entire animal experiments were approved by the Institutional Animal Ethics Committee of Anyang District Hospital Henan Province, Henan, China (ref: 2016/ANDH/imed/A-205) and were performed in strict accordance with the US National Institutes of Health (NIH) guidelines for the care and use of laboratory animals.
\end{abstract}

\section{Ethics statement}

Published research must comply with the guidelines for animal welfare regulations of affiliated Anyang District Hospital Henan Province, Anyang, China. Authors should state in the manuscript text that animal experiments conform to institutional standards (ADHH/16/03/0245).

\section{Induction of myocardial infarction using isoproterenol (ISO)}

Briefly, a total of five sub-groups were formed, each containing 10 rats. The groups were as follows: group 1: control, group 2: ISO + saline, group 3: ISO rats $+10 \mathrm{mg} \mathrm{kg}^{-1}$ linalool, group 4: ISO rats $+20 \mathrm{mg} \mathrm{kg}{ }^{-1}$ linalool, group 5: ISO rats $+40 \mathrm{mg} \mathrm{kg}^{-1}$ linalool. All the animals in the groups, except for the control group, received ISO (150 $\mathrm{mg} \mathrm{kg}^{-1}$ subcutaneously, for two days). After three days of ISO administration, the blood was obtained from the retro-orbital veins. The serum obtained after centrifugation was used for the determination of the levels of $\mathrm{LDH}$ and CK-MB enzymes.

\section{Initiation of the myocardial $I / R$ injury}

For induction of the anaesthesia, a barbiturate derivative was given by intra-peritoneal (ip) injection. Briefly, the coronary artery ligation was performed in accordance with earlier established procedures. A suture made of silk was passed underneath the left anterior descending coronary artery and tied. The considerable changes in the ECG were identified as the marker of a flourishing coronary occlusion. The rats were divided into two groups. The first group was further sub-divided into five groups with six rats in the each group: group 1: nonmyocardial I/R rat, group 2: $\mathrm{I} / \mathrm{R}+$ saline, group 3: ISO rats + $10 \mathrm{mg} \mathrm{kg}^{-1}$ linalool, group 4: ISO rats received $+20 \mathrm{mg} \mathrm{kg}^{-1}$ linalool, group 5: ISO rats $+40 \mathrm{mg} \mathrm{kg}^{-1}$ linalool. After $5 \mathrm{~min}$ of the reperfusion, all the experimental rats received treatment. For example, the first group of animals were used for the determination of various parameters, such as hemodynamic parameter, infarct size and serum levels of Tn-T, cytokines (e.g., TNF- $\alpha$ and IL-6). Whereas, the next group was used for the determination of the level of GPx, SOD, MDA and MPO activities as well as for the western blots analysis.

\section{Langendorff perfusion test}

The rats were anaesthetized with an ip injection of $10 \%$ chloral hydrate, supplemented with $0.1 \mathrm{ml}$ heparin (5000 IU ml $\mathrm{I}^{-1}$ ). The hearts were quickly excised from the heart cavity and arrested in ice-cold perfusion fluid, and the hearts were connected to the Langendorff apparatus by inserting a perfusion cannula into the aorta at a constant pressure $(80 \mathrm{~mm} \mathrm{Hg})$. The hearts underwent retrograde perfusion with Krebs-Henseleit $(\mathrm{K}-\mathrm{H})$ solution $118 \mathrm{mM}$ sodium chloride $(\mathrm{NaCl}), 4.7 \mathrm{mM}$ potassium chloride (KCl), $1.2 \mathrm{mM}$ magnesium sulfate $\left(\mathrm{MgSO}_{4}\right), 1.2 \mathrm{mM}$ (potassium dihydrogen phosphate $\left(\mathrm{KH}_{2} \mathrm{PO}_{4}\right) 25 \mathrm{mM}$ sodium bicarbonate $\left(\mathrm{NaHCO}_{3}\right) 11 \mathrm{mM}$ glucose, $2.5 \mathrm{mM}$ calcium chloride $\left(\mathrm{CaCl}_{2}\right)$ and $2 \mathrm{mM}$ sodium pyruvate), equilibrated to $\mathrm{pH} 7.4$ with a gas mixture comprising $95 \% \mathrm{O}_{2}$ and $5 \%$ carbon dioxide $\left(\mathrm{CO}_{2}\right)$. The perfusion solution was maintained at $37 \pm 0.5{ }^{\circ} \mathrm{C}$ and the temperature was controlled using a water-jacketed organ chamber. A fluid filled balloon was inserted into the LV via the left auricle and connected to a pressure transducer to continuously monitor the changes of $\mathrm{LV}$ pressure. Isolated hearts were stabilized for $30 \mathrm{~min}$ with $\mathrm{K}-\mathrm{H}$ solution, followed by $30 \mathrm{~min}$ of no-flow ischemia and $60 \mathrm{~min}$ of reperfusion to mimic I/R. Resveratrol (RSV; $10 \mu \mathrm{mol} \mathrm{l}^{-1}$ ) was added into K-H solution in the RSV group 15 min prior to the period of ischemia. No ischemia treatment was performed in control group. LVSP, maximal rate of increase of left ventricular pressure $\left(+\mathrm{d} p / \mathrm{d} t_{\max }\right)$, and maximal rate of decrease of left ventricular pressure $(-\mathrm{d} p /$ $\left.\mathrm{d} t_{\text {max }}\right)$ were recorded using a computer-based data acquisition system (RM6240B, Chengdu, China).

\section{Assessment of serum levels of Tn-T, TNF- $\alpha$ and IL-6}

The blood samples were collected after $24 \mathrm{~h}$ of I/R and the serum levels of Tn-T, TNF- $\alpha$ and IL- 6 were measured using enzyme-linked immunosorbent assay (ELISA) kits in accordance with the manufacturer's protocol.

\section{Determination of the levels of MDA, SOD, GPx and MPO activities}

The levels of MDA, SOD, GPx and MPO activities in myocardial tissues affected with ischemia were quantified using kits in accordance with the protocol supplied by the manufacturers.

\section{Cell culture and in vitro $\mathbf{I} / \mathrm{R}$ model}

Fetal rat cardiomyocyte-derived H9c2 cells were purchased from the Type Culture Collection of the Chinese Academy of Sciences, Shanghai, China. Cells were cultured in Dulbecco's Modified Eagle's Medium (DMEM) supplemented with 10\% fetal bovine 
serum (FBS), $100 \mathrm{U} \mathrm{ml}^{-1}$ of penicillin, and $100 \mu \mathrm{g} \mathrm{ml} \mathrm{m}^{-1}$ of streptomycin in $95 \% \mathrm{O}_{2}$ and $5 \% \mathrm{CO}_{2}$ at $37{ }^{\circ} \mathrm{C}$. The culture medium was changed every two days, and cells were subcultured until they reached $60-70 \%$ confluence. The in vitro I/R model was established in $\mathrm{H} 9 \mathrm{c} 2$ cells. $\mathrm{H} 9 \mathrm{c} 2$ cells were treated with $5 \mu \mathrm{mol} \mathrm{l^{-1 }}$ rotenone for $2 \mathrm{~h}$, followed by rotenone free DMEM medium reperfusion for $1 \mathrm{~h}$. Linalool $\left(10 \mu \mathrm{mol} \mathrm{l}^{-1}\right)$ was added into the culture medium $24 \mathrm{~h}$ prior to the rotenone treatment.

\section{Calcein-AM/PI double staining}

H9c2 cells were incubated in phosphate buffered saline (PBS) containing $2 \mu \mathrm{g} \mathrm{ml}^{-1}$ of calcein AM and $1 \mu \mathrm{g} \mathrm{ml} \mathrm{m}^{-1}$ of PI at $37^{\circ} \mathrm{C}$ for $15 \mathrm{~min}$. After washing with PBS, the cells were examined with fluorescence microscopy. Five random fields were observed, and the calcein AM positive area, and the global cells area were measured using ImageJ software (NIH, USA). The calcein AM positive area rate was defined as the percentage of the calcein AM positive area out of the whole cell area.

\section{Cellular apoptosis}

Apoptosis of H9c2 cells was observed using Hoechst 33342 staining ( $5 \mu \mathrm{g} \mathrm{ml}^{-1}$; Sigma, USA) and quantified using flow after cells were stained with annexin V and PI using a fluorescein isothiocyanate (FITC) annexin V apoptosis detection kit (BD Biosciences, USA).

\section{Small interfering RNA (siRNA) transfection}

VEGF-B siRNA was purchased from GenePharma (Shanghai, China). Briefly, H9c2 cells were cultured in DMEM medium (FBS free) for $2 \mathrm{~h}$ before siRNA transfection. VEGF-B siRNA (100 $\mathrm{nM}$ ), or negative control (NC) siRNA was mixed with Lipofectamine 2000 (Invitrogen, USA). The cells were incubated with the transfection mixture for $6 \mathrm{~h}$ and then washed with DMEM medium containing $10 \%$ FBS. The cells were then incubated for an additional $24 \mathrm{~h}$ before harvest.

\section{Western blot analysis}

The heart samples after 24 of $\mathrm{I} / \mathrm{R}$ were mixed in a buffer that consisted of $10 \mathrm{mM}$ tris ( $\mathrm{pH} 7.5$ ), $1.5 \mathrm{mM}$ magnesium chloride $\left(\mathrm{MgCl}_{2}\right), 10 \mathrm{mM} \mathrm{KCl}$, and $0.1 \%$ Triton $\mathrm{X}-100$. The tissues were degraded using homogenization and the nuclei were isolated by centrifugation at $7500 \mathrm{rpm}$. The resulting supernatant was collected and stored at $-80{ }^{\circ} \mathrm{C}$ before the analysis. The nuclear proteins were extracted at $4{ }^{\circ} \mathrm{C}$ by resuspending the nuclei pellet in a buffer consisting of $20 \mathrm{mM}$ tris (pH 7.5), 20\% glycerol, $1.5 \mathrm{mM} \mathrm{MgCl}_{2}, 420 \mathrm{mM} \mathrm{NaCl}, 0.2 \mathrm{mM}$ ethylenediaminetetraacetic acid (EDTA), and $0.1 \%$ Triton X-100, followed by $1 \mathrm{~h}$ incubation and after microcentrifugation for $15 \mathrm{~min}$, the supernatant was collected. The concentration of protein was estimated using a bicinchoninic acid (BCA) assay kit (ThermoFisher, USA). Thereafter, the total protein extract (50 $\mu \mathrm{g})$ was separated on $15 \%$ sodium dodecyl sulfate polyacrylamide (SDSPAGE) gel and by probing with rabbit anti-phosphor-NF- $\kappa \mathrm{B}$ and anti-phosphor-I $\kappa \mathrm{B}-\alpha$ using anti- $\beta$-actin antibody (control),
VEGF-B, MnSOD (Abcam, USA), phosphorylated (Ser473) and total Akt, phosphorylated (Ser 9) and total GSK3 $\beta$ (Cell Signaling Technology, USA), Bax and $\beta$-actin (Santa Cruz Biotechnology, CA, USA).

\section{Histopathological analysis}

Briefly, the hearts of the experimental animals were sectioned and then fixed in $10 \%$ formalin and then the sections were embedded in paraffin and then cut in sections. The resulting sections were stained with hematoxylin and eosin (H\&E) stain after fixation and evaluated under a microscope $(100 \times)$.

\section{Echocardiography}

The echocardiography (echo) was performed on each of the rats on linalool at a single dose of $10 \mathrm{mg} \mathrm{kg}^{-1}$ to evaluate the effects on the cardiovascular morphology and function. Under anaesthesia with sodium pentobarbital (30 mg kg-1, ip), a $12 \mathrm{MHz}$ transducer (HP SONOS 5500, Hewlett Packard, Inc., Andover, MA, USA) was used to obtain two-dimensional (2D) images of the LV at long and short axes. LV mass (LVM) and LV posterior wall thickness were measured from the M-mode LV tracings. LV ESV and LV EDV were calculated from the 2D images using a modified Simpson's rule. The LV ejection fraction (EF) was calculated from the EDV and ESV. The cardiac index (CI) was calculated as cardiac output adjusted for body weight.

\section{Statistical analysis}

The experimental data were expressed as mean $\pm \mathrm{SD}$, using the one-way analysis of ANOVA followed by the Tukey's test. The $P$ value $<0.05$ was considered as statistically significant.

\section{Conclusion}

In conclusion, the theory that linalool protects the cardiac system of the rats in myocardial I/R injury and exerts its beneficial role via a number of mechanisms has been corroborated. However, its pharmacological significance in $\mathrm{I} / \mathrm{R}$ warrants further investigation in terms of its exact mechanism of action. The present study may serve as a template for the further studies on linalool for I/R injury.

\section{Conflict of interest}

The authors declare no conflict of interest.

\section{Notes and references}

1 V. T. Nkomo, J. M. Gardin, T. N. Skelton, J. S. Gottdiener, C. G. Scott and M. Enriquez-Sarano, Lancet, 2006, 368, 1005-1011.

2 A. Boutayeb and S. Boutayeb, Int. J. Equity Health., 2005, 4, 2. 3 A. E. Moran, K. Y. Tzong, M. H. Forouzanfar, G. A. Roth, G. A. Mensah, M. Ezzati, C. J. L. Murray and M. Naghavi, Glob. Heart., 2014, 9, 91-99.

4 H. D. White and D. P. Chew, Lancet, 2008, 372, 570-584.

5 G. Ertl and S. Frantz, Cardiovasc. Res., 2005, 66, 22-32. 
6 E. D. Grech, C. I. Jack, C. Bleasdale, M. J. Jackson, M. Baines, E. B. Faragher, C. R. Hind and R. A. Perry, Coron. Artery Dis., 1993, 4, 769-774.

7 D. Bell, M. Jackson, J. J. Nicoll, A. Millar, J. Dawes and A. L. Muir, Br. Heart J., 1990, 63, 82-87.

8 D. M. Ansley and B. Wang, J. Pathol., 2013, 229, 232-241.

9 N. G. Frangogiannis, C. W. Smith and M. L. Entman, Cardiovasc. Res., 2002, 53, 31-47.

10 H. Yin, L. Xu and N. A. Porter, Chem. Rev., 2011, 111, 59445972.

11 L. L. De Zwart, J. H. N. Meerman, J. N. M. Commandeur and N. P. E. Vermeulen, Free Radical Biol. Med., 1999, 26, 202226.

12 T. P. A. Devasagayam, J. Tilak, K. K. Boloor, K. S. Sane, S. S. Ghaskadbi and R. D. Lele, J Assoc Physicians India, 2004, 52, 794-804.

13 G.-H. Seol, P. Kang, H. S. Lee and G. H. Seol, BMC Neurol., 2016, 16, 4-9.

14 M. Lavy, A. Zuker, E. Lewinsohn, O. Larkov, U. Ravid, A. Vainstein and D. Weiss, Mol. Breed., 2002, 9, 103-111.

15 E. Elisabetsky, J. Marschner and D. Onofre Souza, Neurochem. Res., 1995, 20, 461-465.

16 A. M. Kamatou and G. P. P. Viljoen, Nat. Prod. Commun., 2008, 3, 1183-1192.

17 K. M. Ver Elst, H. D. Spapen, D. N. Nguyen, C. Garbar, L. P. Huyghens and F. K. Gorus, Clin. Chem., 2000, 46, 650-657.

18 N. Van Der Vekens, A. Decloedt, S. Ven, D. De Clercq and G. van Loon, J. Vet. Intern. Med., 2015, 29, 348-354.

19 M. Dizdaroglu, P. Jaruga, M. Birincioglu and H. Rodriguez, Free Radic. Biol. Med., 2002, 32, 1102-1115.

20 J. R. Speakman and C. Selman, BioEssays, 2011, 33, 255-259.
21 L. L. de Zwart, J. H. Meerman, J. N. Commandeur and N. P. Vermeulen, Free Radic. Biol. Med., 1999, 26, 202-226. 22 P. Libby, Circulation, 2002, 105, 1135-1143.

23 Y. Feng and W. Chao, Int. J. Inflam., 2011, 2011, 170352.

24 D. J. Marchant, J. H. Boyd, D. C. Lin, D. J. Granville, F. S. Garmaroudi and B. M. McManus, Circ. Res., 2012, 110, 126-144.

25 K. H. Melamed and S. Z. Goldhaber, Circulation, 2014, 130, e334-e336.

26 A. Wullaert, M. C. Bonnet and M. Pasparakis, Cell Res., 2011, 21, 146-158.

27 M. Sangeetha, M. S. Pillai, L. Philip, E. G. Lakatta and K. Shivakumar, Exp. Cell Res., 2011, 317, 899-909.

28 L. Zentilin, U. Puligadda, V. Lionetti, S. Zacchigna, C. Collesi, L. Pattarini, G. Ruozi, S. Camporesi, G. Sinagra, M. Pepe, F. A. Recchia and M. Giacca, FASEB J., 2010, 24, 1467-1478.

29 L. Sun, C. K. Isaak, Y. Zhou, J. C. Petkau, O. Karmin, Y. Liu and Y. L. Siow, Life Sci., 2012, 91, 151-158.

30 B. Wang, J. Shravah, H. Luo, K. Raedschelders, D. D. Y. Chen and D. M. Ansley, Biochem. Biophys. Res. Commun., 2009, 389, 105-111.

31 K. Radad, W. D. Rausch and G. Gille, Neurochem. Int., 2006, 49, 379-386.

32 N. Li, K. Ragheb, G. Lawler, J. Sturgis, B. Rajwa, J. A. Melendez and J. P. Robinson, J. Biol. Chem., 2003, 278, 8516-8525.

33 M. Le Grand, A. Rovini, V. Bourgarel-Rey, S. Honore, S. Bastonero, D. Braguer and M. Carre, Oncotarget, 2014, 5, 3408-3423.

34 J. Ryder, Y. Su and B. Ni, Cell. Signalling, 2004, 16, 187-200. 35 M. B. Preda and A. Burlacu, Comp. Med., 2010, 60, 443-447. 